\title{
Review Article \\ Quaternary Salts of Chitosan: History, Antimicrobial Features, and Prospects
}

\author{
Douglas de Britto, ${ }^{1}$ Rejane Celi Goy, ${ }^{1}$ Sergio Paulo Campana Filho, ${ }^{2}$ and Odilio B. G. Assis ${ }^{1}$ \\ ${ }^{1}$ Embrapa Instrumentação Agropecuária, Brazilian Agricultural Research Corporation, Rua XV de Novembro, 1452, P.O. Box 741, \\ 13560-970 São Carlos, SP, Brazil \\ ${ }^{2}$ Instituto de Química de São Carlos, USP, Avenida Trabalhador São-Carlense, 400, P.O. Box 780, 13560-970, São Carlos, SP, Brazil
}

Correspondence should be addressed to Douglas de Britto, britto@cnpdia.embrapa.br

Received 28 January 2011; Revised 14 April 2011; Accepted 27 May 2011

Academic Editor: José das Neves

Copyright (C) 2011 Douglas de Britto et al. This is an open access article distributed under the Creative Commons Attribution License, which permits unrestricted use, distribution, and reproduction in any medium, provided the original work is properly cited.

Recently, increasing attention has been paid to water-soluble derivatives of chitosan at its applications. The chemical characteristics and the antimicrobial properties of these salts can play significant role in pharmacological and food areas mainly as carriers for drug delivery systems and as antimicrobial packaging materials. In the current paper, a historical sequence of the main preparative methods, physical chemistry aspects, and antimicrobial activity of chitosan quaternized derivatives are presented and briefly discussed. In general, the results indicated that the quaternary derivatives had better inhibitory effects than the unmodified chitosan.

\section{Background}

One of the first reports about methylation process of chitosan was presented by Wolfrom et al. in their study on carboxyl-reduced heparin published in 1963 [1]. Despite employing a very methylant agent (dimethylsulfate), only a 3,6-O-methylated product was claimed by the authors. In the seventies, Nudga et al. studied a series of $\mathrm{N}$ alkylated chitosans [2-4] and described the preparation of a derivative with a $78 \%$ of quaternary amino sites. Then, Muzzarelli and Tanfani, in 1985 [5], prepared N-trimethyl chitosan iodide in a controlled three-step reaction: (a) started by a preparation of an $\mathrm{N}$-alkyl chitosan via reductive alkylation, in which the chitosan amino groups react with appropriated aldehyde, generating a Schiff's base; (b) this compound is treated with a reducing agent, to yield the corresponding $\mathrm{N}$-alkyl chitosan (c) then an overmethylation with an alkyl halide is carried out, generating, finally, the quaternary salt. With these sequences Muzzarelli and Tanfani obtained N,N,N-trimethyl chitosan (TMC) by reacting $\mathrm{N}$ permethylated chitosan, which was previously prepared by treating chitosan with formaldehyde followed by reduction with sodium borohydrade and trimethylation with methyl iodide. Although, according to the authors, the product $60 \%$ trimethylated was not water soluble and characterized only with ${ }^{13} \mathrm{C}$ NMR and elemental analysis. This effort was made, aiming its application as antibiotic and ion exchange material.

In the following year, Domard et al. [6], also reacting chitosan with methyl iodide, gave an important contribution mainly on the role of the reagents in the quaternization. They established that the combination of $\mathrm{N}$-methyl-2-pyrrolidone (NMP) and $\mathrm{NaOH}$ favors the quaternization better than sole addition of organic bases, for example, triethylamine. In order to understand the chemical structure of the TMC, several papers were published, emphasizing the features and signal changes as observed by nuclear magnetic resonance spectroscopy $[7,8]$. At this time, three important branches of application for TMC have emerged, to be known: (i) as gene delivery tool; (ii) as absorption enhancer for hydrophilic drugs transport across epithelium (iii) for cosmetics applications.

The first topic started back in $1996-97$ by the publications from Murata et al. $[9,10]$ who measured the cytotoxic activity and the formation of polyelectrolyte complex with DNA. Those works were based on the derivative synthesis 
as proposed by Domard et al. [6]. After a long period of latency regarding this specific application, in 2005 Kean et al. [11] returned to this area, publishing results of a study about the toxicity and transfection efficiency of TMC derivatives with respect to the degree of trimethylation. After that, several other papers have been published in the field, highlighting the polyelectrolyte complex (PEC) formation [12]; aspects of nanoparticles cytotoxicity [13]; structureactivity relationship determination $[14,15]$; reviews of use of chitosan derivatives as functional polymers [16-18].

The second issue began with Kotze et al. [19] in 1997 by reporting that TMC, as drug excipient, had a superior efficiency as absorption enhancer for hydrophilic drugs across intestinal epithelia than the chitosan itself. This potential for pharmacological applications increased considerably the interest for this polyelectrolyte. Aiming at better efficiency, the synthetic path was deeply studied, allowing, consequently, a better comprehension of its chemical structure [20-30]. The absorption enhancer property of the TMC did not confine only to intestinal epithelia but for other epithelial tissues. It showed also to be efficient, as documented for buccal mucosa [31, 32], mammalian airway [33], rabbit cornea [34], and derma [35]. Despite the huge amount of publications and data on chitosan quaternization, the synthetic route had remained almost the same, generally with a reaction involving a suspension of NMP and methyl iodide. Furthermore, these studies also demonstrate (see, e.g. $[25,29])$ that strong inorganic bases, such as $\mathrm{NaOH}$, are more efficient for quaternization than organic ones. As TMC gained attention for use in oral drug delivery, some reviews on the subject have appeared [16, 28, 36-38].

The last application can be related to the publication of Lang et al. [39] regarding the synthesis of quaternary salts for use as additive in cosmetic products. The authors proposed alternative synthetic routes as well as new applications for the derivative. One of the suggested methodologies was the covalent addition of a substituent containing a quaternary ammonium group. It could be achieved by reacting chitosan with a quaternary ammonium epoxide, such as glycidyltrimethylammonium chloride. The main focus was the cosmetic market, as evidenced by several patents refereed in that paper.

More recently, an important branch of application for chitosan quaternary salt related to antimicrobial action has gained attention. It started by Kim et al. [40] testing several chitosan quaternary salt against Staphylococcus aureus. The synthetic path was based on that proposed by Muzzarelli and Tanfani [5]. In this way, the authors described the reaction of chitosan with formaldehyde, butyraldehyde, noctylaldehyde, and n-dodecylaldehyde, treated the resulting Schiff's bases with sodium borohydrade, obtaining the quaternary salts via methyl iodide synthetic route. In fact, the antibacterial activity of the prepared salts was higher than that found for chitosan itself and increased with increasing chain length of the alkyl substituent. Following this line, in 2001, Jia et al. [41], also prepared several quaternary chitosan salts and tested against gram-negative bacteria Escherichia coli. It was seen that these salts exhibited higher in vitro activity against $E$. coli than chitosan, mainly in acid medium. Particularly, other combinations including alkyl, aryl moieties and carboxymethylation in chitosan quaternary salt also showed to be efficient against gram-negative and gram-positive bacteria [42-45].

With respect to its physical and chemical properties, works have reported the chemoselectivity with methyl iodide [46], the thermal degradation [47], the viscosity behavior [48], new synthetic route via dimethylsulfate $[49,50]$, the degree of quaternization via solid state ${ }^{13} \mathrm{C}$ NMR [51], and procedures for preventing the occurrence of O-methylation $[52,53]$.

Finally, the utmost research is the synthesis and application of chitosan quaternary salts as nanoparticles. It started from the work of Xu et al. [54], who reported the preparation of quaternary salt via reaction between glycidyl-trimethylammonium chloride and chitosan and the formation of nanoparticles based on ionic gelation process with sodium tripolyphosphate (TPP). They described nanoparticles in the size range of 110-180 nm with drug entrapment efficiency up to $90 \%$, for evaluation of bovine serum albumin as a model drug. Several other important applications have emerged for TMC nanoparticles obtained by ionic gelation with TPP, such as nasal [55-57] and oral [58] vaccine delivery system; protein carrier [59-61], and insulin releaser [62]. Then, several methods for the preparation and applications of TMC were reported, as: (i) by emulsion-diffusionevaporation technique for gene transfer process [63]; (ii) by electrostatic self-assembling between TMC and insulin [64, 65] and cysteine [66], for controlled release applications; (iii) synthesis and characterization of gold, silver, and platinum TMC nanoparticles [67]; (iv) via ionotropic gelation with alginate for drug delivery [61, 68-70]; (v) alkyl chitosan salts micelles (or nanomicelles) formed via ultrasonication in aqueous media for nutraceuticals and functional foods $[71,72]$; (vi) via ionotropic gelation with $\operatorname{poly}(\gamma$-glutamic acid) for insulin controlled transport [73].

In spite of this vast literature on production and applications of TMC nanoparticles for delivery system, it is reported that TMC nanoparticles loaded with insulin were found to be less effective in permeating epithelial cells than the corresponding TMC in its free soluble form (not as nanoparticles) [74]. The reduced available amount of positive charge at the surface of the nanoparticles was claimed as responsible for this lower performance. Moreover, an important finding in that research was the strongest ability of TMC in opening the tight junction in comparison with the parent chitosan and other quaternary salts, for example, dimethylethyl chitosan and diethylmethyl chitosan.

\section{Physical-Chemical Aspects}

Chitin and chitosan are $\beta(1 \rightarrow 4)$ glycans whose chains are formed, respectively, by 2-acetamide-2-deoxy-D-glucopyranose and 2-amino-2-deoxy-D-glucopyranose units. Chitosan is generally prepared by the deacetylation of chitin, and, in fact, none of them can be considered a homopolymer. Chitin, regularly isolated from the carapaces of marine animals such as crabs and shrimps, contains some 
fraction (approximately 5-10\%) of 2-amino-2-deoxy-Dglucopyranose units. Completely deacetylated chitosan is, however, rarely prepared due to the simultaneous occurrence of extensive depolymerization.

The chitosan's amino group behaves as nucleophile that bonds to and yields products with a variety of electrophiles, so the methylation reaction proceeds via electrophilic substitution of nitrogen. The most common electrophiles already reported on chitosan methylation are alkyl halides ( $\mathrm{R}-$ $\left.\mathrm{C}^{\delta+} \mathrm{H}_{2}-\mathrm{X}\right)$ and dialkyl sulfate $\left(\mathrm{R}-\mathrm{C}^{\delta+} \mathrm{H}_{2}-\mathrm{SO}_{4}-\mathrm{C}^{\delta+} \mathrm{H}_{2}-\mathrm{R}\right.$ ). In both cases the reaction proceeds presumably by a $\mathrm{S}_{\mathrm{N}} 2$ mechanism and liberates $\mathrm{H}^{+}$as a by-product. However, low $\mathrm{pH}$ values affect the forward reaction in two aspects: first, decreasing the substitution degree and, second, promoting the glycoside bond cleavage. The first event occurs when $\mathrm{H}^{+}$is captured by the unshared electron pair of the nitrogen, stopping the reaction at the amino site. The last event causes chain depolymerization, yielding low molecular weight derivatives [48]. These problems can be overcome by a proper addition of strong bases $[6,7,25]$. On the other hand, the added $\mathrm{OH}^{-}$base is also a nucleophile that can react with the electrophile and produces alcohols. It seems that the slow addition of the strong base during the course of the reaction is the best way to avoid this problem.

The main parameters that characterize a chitosan's derivative are its average degree of quaternization, $\overline{D Q}$, and molecular weight. The $\overline{D Q}$ is usually determined by ${ }^{1} \mathrm{H}$ NMR spectroscopy [22, 24, 46], although potentiometric and conductimetric methods have also been proposed [41, $46,48]$. As the reaction is conducted in a heterogeneous medium, monomethylated, dimethylated, and trimethylated species are generated randomly. This has complexed and even leaded to misinterpretation of the ${ }^{1} \mathrm{H}$ NMR spectrum. Although, solid state $\mathrm{CP}-\mathrm{MAS}{ }^{13} \mathrm{C} \mathrm{NMR}$ technique has been emerged as an alternative method to calculate TMC's $\overline{D Q}$ [51]. Despite the usefulness of FTIR spectroscopy in determining the degree of acetylation of chitosan [75] on TMC characterization, it has been limited to qualitative analysis [40, 41, 44, 47, 49]. Regarding the molecular weight, comparative viscosimetric studies have been adopted [25], but, as increasing the applicability of such derivatives, absolute method based on Gel Permeation Chromatograph (GPC) has given precise data $[15,27,42,76-82]$. In the following, the main features of these techniques in TMC characterization are discussed.

Sample preparation for FTIR spectroscopy can be accomplished by $\mathrm{KBr}$ pellets or casting thin film on acrylic dish. The last method, however, makes use of the excellent film ability of such polymer and gives good spectra with low noise. Two main differences between the parent chitosan and TMC FTIR occur in the interval of $1700-1200 \mathrm{~cm}^{-1}$ (see Figure 1). First, the TMC's spectra show a band near $1475 \mathrm{~cm}^{-1}$, " $A$ ", correspondent to asymmetrical stretching of $\mathrm{C}-\mathrm{H}$ in the methyl groups. This band is absent in the spectrum of the starting chitosan. Second, the band assigned to angular deformation of $\mathrm{N}-\mathrm{H}$ in amino groups (near $1590 \mathrm{~cm}^{-1}$, " $B$ ") is reduced for the derivatives, and, generally, is overlaid by the signal at $1630 \mathrm{~cm}^{-1}$ (carbonyl stretching of acetamide moiety, " $C$ "). The major problem in using FTIR in

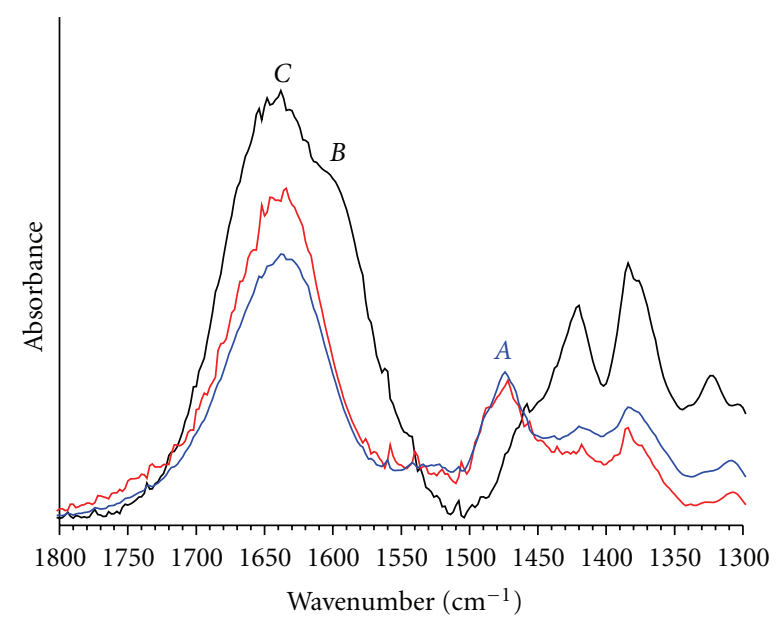

\begin{tabular}{l} 
_ Chitosan \\
- TMC1 \\
\hline TMC2
\end{tabular}

Figure 1: Typical FTIR spectra of chitosan and TMC.

quantitative analysis may be related to lack of proportionality between the signal " $A$ " and the $\overline{D Q}$. As seen in Figure 1, the two TMC derivatives have different $\overline{D Q}$ but the intensity of the signal " $A$ " is equal in two samples [49].

The ${ }^{1} \mathrm{H}$ NMR spectroscopy is also a useful tool in characterization and has been largely used in $\overline{D Q}$ calculation. Some misinterpretation regarding peaks assignments was raised before [8] but corrected in a subsequent paper [22]. Currently, the peaks assignments shown in Figure 2 are accepted as the correct one. Although, for certain applications, not only the $\overline{D Q}$ is important, but also the degree of dimethylation and O-methylation as well. For this knowledge, ${ }^{1} \mathrm{H}$ NMR spectroscopy has been used $[15,77] .{ }^{1} \mathrm{H}$ NMR spectroscopy was also used as quantitative technique in the characterization of O-methyl free TMC derivatives $[46,52,78,79]$. The strategy for such attempt was based on the method described by Muzzarelli and Tanfani [5] with some modification. According to the authors, the twostep reaction (dimethylation with formic acid-formaldehyde followed by a mild methylation with iodomethane without addition of strong $\mathrm{OH}^{-}$base) not only avoided the Omethylation reaction but also prevented the chain scission. However, some limitations of this technique in substitution calculation were discussed recently [51] and are related mainly to the low intensity of the proton linked to $\mathrm{C} 1$ of the glycoside ring, generally took as reference signal [52]. This can induce a super estimation of such parameters.

The solid-state CP-MAS ${ }^{13} \mathrm{C}$ NMR spectroscopy, which combines the techniques of proton dipolar decoupling (DD), magic angle spinning (MAS), and crosspolarization (CP), has emerged as an alternative tool in TMC characterization and $\overline{D Q}$ calculation [49-51]. A methylated chitosan may show the following evidences (Figure 3): (a) $106.1 \mathrm{ppm}$, attributed to $\mathrm{C} 1$ signal of the glycoside ring when there is no substitution on the near amino group; (b) $100.4 \mathrm{ppm}$, attributed to $\mathrm{C} 1$ signal when there is substitution on the near 


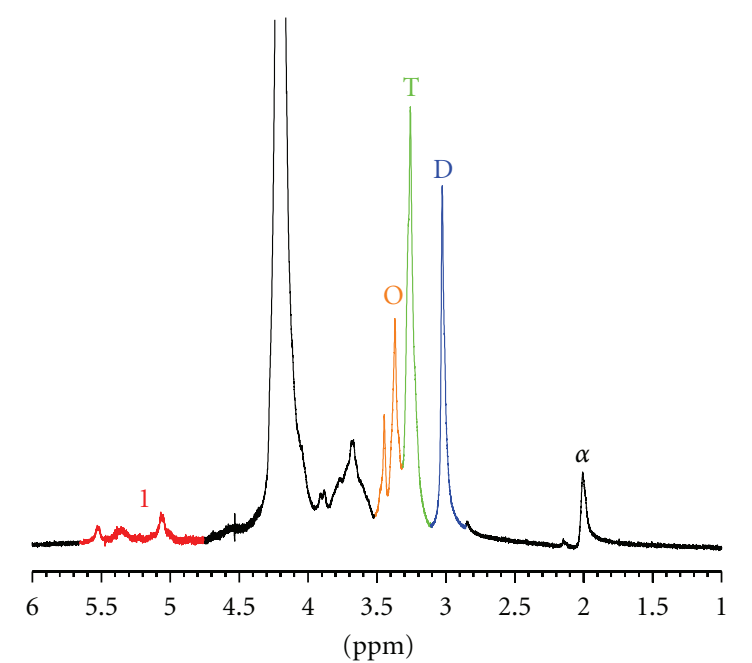

FIgUre 2: Typical ${ }^{1} \mathrm{H}$ NMR spectrum of TMC. For chemical structure and legends, see Figure 3.

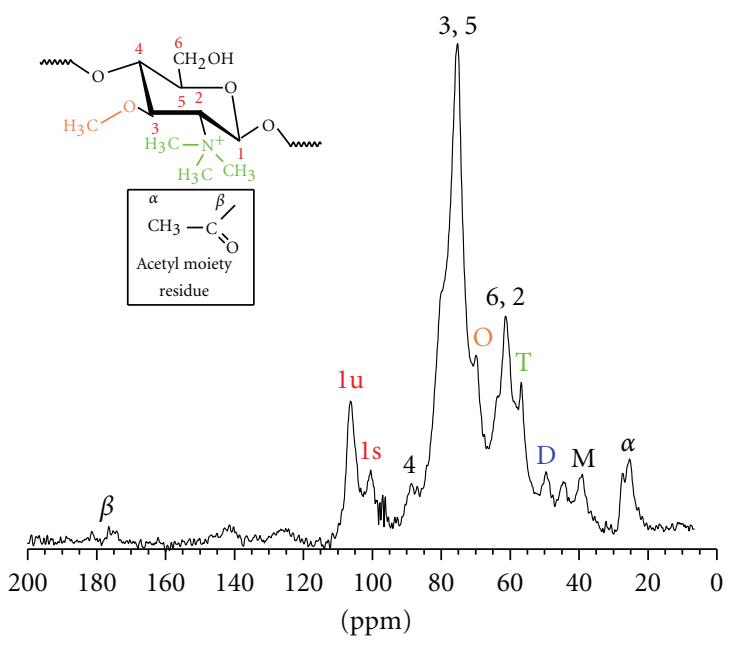

Figure 3: Typical solid state CP-MAS ${ }^{13} \mathrm{C}$ NMR spectrum of TMC. The labels stand for 1u: C1 (amino unsubstituted); 1s: C1 (amino substituted); O :O-methylated; T:N,N,N-trimethylated; D:N,Ndimethylated $\mathrm{M}: \mathrm{N}$-monomethylated signals.

amino group; (c) $37.9 \mathrm{ppm}$, attributed to carbon of methyl groups in N-monomethylated site; (d) $48.1 \mathrm{ppm}$, correspondent to carbon of methyl groups in N,N-dimethylated site; (e) $56.4 \mathrm{ppm}$, related to the carbon of methyl groups in N,N,N-trimethylated site (f) $68.5 \mathrm{ppm}$, correspondent to the carbon of methyl groups in O-methylated site. In fact, the signals labeled as "1u", " $1 \mathrm{~s}$ ", and "T" showed reasonable proportionality according to degree of substitution [82]. Such technique was also useful to characterize other chitosan quaternary salts, for example, N-butyl-N,Ndimethylchitosan, N-octyl-N,N-dimethylchitosan, and $\mathrm{N}$ dodecyl-N,N-dimethylchitosan [50].

Degradations which occur during the reaction can be assessed by measuring the intrinsic viscosity, $[\eta]$, since it

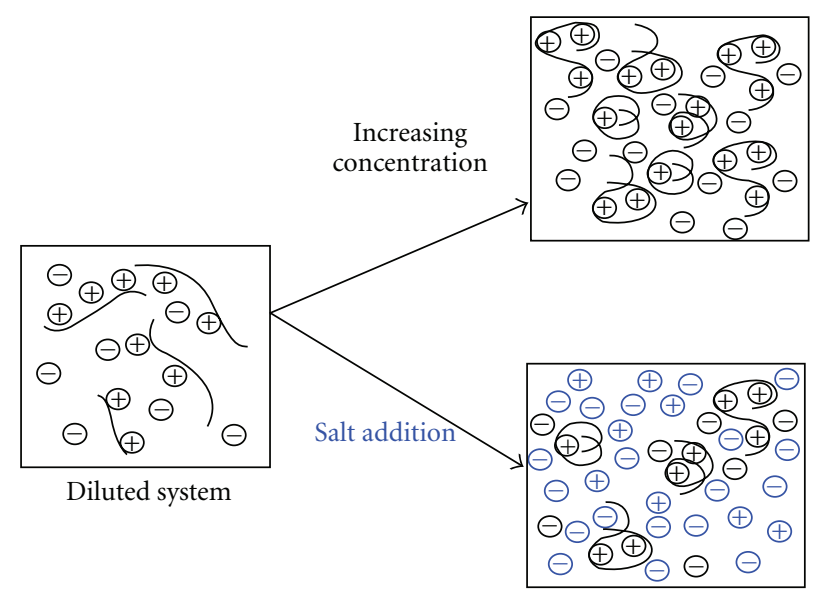

FIGURE 4: Illustration of the different chain conformations of a polyelectrolyte in function of the concentration and ionic strength.

is related to the average molecular weight by the MarkHouwink equation, $[\eta]=K \bar{M}_{v}^{a}$. The drop in [ $\left.\eta\right]$ can be of $90 \%$ in comparison with parent chitosan, depending on the reaction condition [25], until of only 5\% [8]. But, in most of the cases, intermediate values within this range are common $[27,48,49,76,77,82]$. Absolute molecular weight technique (GPC) also shows such depolymerization, situating $M_{w}$ near $1.0-3.0 \mathrm{~g} / \mathrm{mol} \times 10^{5}[27,76,77,82]$. In fact, a plot of $\log [\eta]$ versus $\log M_{w}$ showed values of 0.39 and $2.14 \times 10^{-4}$ for the empirics Mark-Houwink's parameters $a$ and $K$, respectively [77]. However, instead of a drop, Verheul et al. [52] found a slight increase in $M_{w}$, rising of $42 \mathrm{kDa}$ up to $84 \mathrm{kDa}$, which was attributed to limited or even absence of chain scission during reaction by the method of O-methylation free.

The usefulness of viscosity data is not limited to molecular weight estimation, but it spread light on chain conformation as well. Chain conformation, in its turn, can help to understand the antimicrobial activity of the polymer. Particularly in the case of cationic polyelectrolyte, as chitosan and its quaternary salts, the viscosity, in aqueous solution free of added electrolytes, shows an apparent paradoxical behavior called polyelectrolytic effect in which the viscosity increase, as the dilution increase, (Figure 4). The charged groups repeal each other, causing chain expansion, increasing the hydrodynamic volume and, consequently, increasing the viscosity. In the presence of added electrolytes, the charges will be screened, and, consequently, the polyelectrolyte chain will adopt a coiled conformation.

TMC itself shows the polyelectrolyte effect (Figure 5) and the viscosimetric study of the interaction of TMC with other charged species like surfactant (Figure 5), anionic polyelectrolyte, and other complexant polymers can explain the mode of action between the quaternary salt and the cell wall of a microorganism. Further studies must be developed in this area.

The hydrophilic character is another important property of chitosan quaternary salt that shows the net force presented in the surface of a smooth solid film. This property is useful in protecting coating experiments in which the interactions 


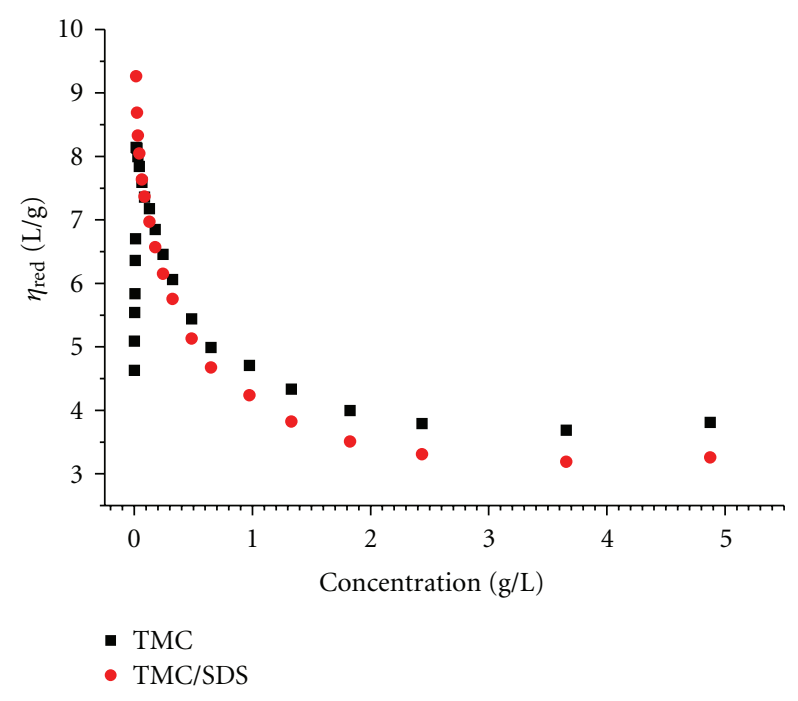

Figure 5: Polyelectrolytic effect of TMC and TMC/sodium dodecyl sulfate (SDS) complex in aqueous solution (adapted from [83]).

existent in the interfaces peel/coating film/microorganism spores play an important role. It is generally measured by contact angle technique and expressed in terms of wettability $[49,84]$. For TMC, a sharp decrease in the contact angle values was found when compared with the parent sample due the presence of permanent positive charges which increased the hydrophilic character of the quaternary salts. On the other hand, the methyl groups, having apolar character, also contribute to hydrophilic character decreasing, as seen for highly substituted samples [84].

\section{Antibacterial Action of Chitosan Quaternary Salts}

The mode of action of antimicrobial activity of chitosan derivatives is strictly linked with that described for chitosan itself [85-87]. In fact, the main objective of the derivatives synthesis is to enhance such intrinsic property of chitosan. Particularly for quaternary salts, the advantage over the parent chitosan is attributed to its permanent positive charge and the synergetic effect of the pendant alkyl moiety. Further, the solubility of chitosan at physiological $\mathrm{pH}$ is low, while for the quaternary salts the solubility is high both in acid and basic conditions.

In fact, the better antibacterial activity of quaternary salt cannot rely only on charge density because at acid medium the chitosan chain is almost completely protonated. As pointed out by $\mathrm{Xu}$ et al. [44], it is necessary also to consider the degree of ionization and the chain conformation. For example, at moderated acid conditions, the repulsive forces among quaternary groups $\left(-\mathrm{N}^{+}\left(\mathrm{CH}_{3}\right)_{3}\right)$ are weaker than that among protonated chitosan amine groups, which increases the chain flexibility and facilitates the interaction with bacteria cell envelope. Despite this, the increase of the $\overline{D Q}$ is not a guarantee of better antibacterial activity. It depends on the $\mathrm{pH}$. Some investigations showed that the antibacterial efficiency decreased as the $\overline{D Q}$ increased at acid conditions, but increased as the $\overline{D Q}$ increased at neutral conditions $[44,88]$. Here, the knowledge of chain conformation is fundamental for a better comprehension of this behavior.

The cell wall of bacteria is a complex structure made mainly of lipopolysaccharide (gram-negative) and peptidoglycan associated with teichoic acid (gram-positive), both having anionic groups (phosphate, carboxyl, Nacetylglucosamine, $\mathrm{N}$-acetylmuramic acid, etc.) that can interact (hydrogen bond, electrostatic, etc) with the polycationic structure of the quaternary salt. The chelant effect of quaternary salts on divalent cations present on cell wall also contributes to disrupt the integrity of the membrane [85].

The presence and length of alkyl moiety on amine group is another relevant question on such derivatives. The hydrophobic affinity between the alkyl chain and phospholipids of the bacterial membrane has assumed to enhance the antibacterial activity $[40,41,43,89]$. In this attempt, several chitosan derivatives were synthesized, involving several paths as alkylation, covalent addition of a substituent containing a quaternary ammonium group and extent methylation. Such derivatives have a very complex structure with variable antibacterial activity $[90,91]$. However, a series of N-(2quaternary ammoniumyl) acyl derivatives with different chain moiety did not exhibit better antibacterial activity than the TMC [45]. In another study, the methylated N-aryl chitosan did not improve so much the antibacterial activity, with similar results that are found for pure TMC [42].

E. coli and S. aureus have been adopted as model of gramnegative and gram-positive bacteria, respectively, in most of the studies, with MIC (Minimum Inhibitory Concentration) as lower as $0.125 \mu \mathrm{g} / \mathrm{mL}$ for E. coli and $0.0625 \mu \mathrm{g} / \mathrm{mL}$ for S. aureus [44]. However, other bacteria as Enterococcus facialis and Pseudomonas aeruginosa have shown susceptible to TMC, with MIC of 128 and $256 \mu \mathrm{g} / \mathrm{mL}$ respectively [45]. Streptococcus mutans, responsible for dental caries in humans, was also susceptible to chitooligosaccharide quaternized via covalent addition of glycidyl trimethylammonium chloride [92]. In the presence of a $0.1 \%$ solution, the quaternary derivative inhibited near $90 \%$ of the colonies growth, while the unmodified counterpart only $10 \%$ after 5 hours of exposure. Belalia et al. [93] also gave an important contribution, studding the action of quaternary salt against Listeria monocytogenes and Salmonella typhimurium in their attempt to improve the properties of biocomposite for packaging purposes. The derivative was based on Muzzarelli and Tanfani [5] method and showed inhibition of 96\% of $L$. monocytogenes and $100 \%$ of S. typhimurium development.

The most important issue from now is to establish the effectiveness of such derivatives at in situ experiments. The antibacterial activity of chitosan has been proved in several in situ experiments as food preservative, packaging material, edible film and coating, wound dressing materials, cotton fabrics, and many others [86]. In this line, experiments with TMC were reported, showing the effectiveness of electrospun mats of TMC/poly(vinyl alcohol) [94] and mats of TMC/poly(vinyl pyrrolidone) [95] against E. coli and $S$. aureus. The potentiality of such mats was regarding wounddressing applications. Antibacterial activities of finished 
cotton fabrics impregnated with chitosan derivative were also evaluated, although the synthesis path was similar to that complex one cited above, based on alkylation, covalent addition of a quaternary substituent, and further methylation [96]. Related to food area, the work of Belalia et al. [93] contributed to knowledge in elaboration of effective antibacterial biopackagings with improved mechanical property.

In this way, the antibacterial activity of cast TMC film helps to understand the behavior of in situ conditions. For this, a qualitative test can be performed by agar diffusion method [97]. Film cuts were placed on the medium, and the inhibitory activity was measured based on the average diameter of the clear inhibition zone. Figure 6 illustrates the measurable zone.

The diameters of inhibitory zones surrounding film discs as well as the contact areas of edible films with agar surface were reported with significant results. A wide clear zone on solid media has been observed for S. aureus growth inhibition, whereas inhibition for $E$. coli is not effective, in some way confirming better antibacterial activity against gram-positive bacteria. The film concentration also appears to be important, mainly for the TMC, whose inhibition zone increases exponentially with the concentration (Figure 7). For commercial chitosan, the bacterial activity is inferior and not dependent on the concentration.

\section{Chitosan Quaternary Salt and Antifungal Activity}

Similar to antibacterial properties, the derivative synthesis has the main objective to enhance the antifungal property of chitosan largely reported in the literature [87, 98-100]. Particularly for fungi, such derivative study is more important once chitosan generally has a stronger antimicrobial activity against bacteria rather than against fungi [101]. Common plant pathogenic fungi such as Botrytis cinerea, Penicillium expansum, Rhizopus stolonifer, Penicillium digitatum, and Penicillium italicum, among many others, have been tested with chitosan, owing to its impact in the agricultural business.

In order to enhance the chitosan antifungal activity some methodology has been proposed. For example, the synergistic effect of microbial antagonists, for example, Candida saitoana Cryptococcus laurentii, enhanced significantly the antifungal activity of chitosan [101]. Accordingly, chitosan was effective against $P$. expansu spore germination in vitro and in vivo when introduced on the wound of Fuji apple (Malus domestica Borkh.). They found a complete inhibition of $P$. expansum spore germinations at concentrations of $0.3 \%$ or above of chitosan for in vitro test. On the other hand, after addition of $C$. laurentii antagonist the inhibitory concentration dropped to $0.1 \%$. Addition of essential oil [102] or changing the organic acid, for example, acetic, sorbic, propionic, lactic, and glutamic acids [103], were also proposed to enhance the chitosan antifungal activity, representing an actual alternative to synthetic fungicide such as thiabendazole.
Finally, the chemical modification of chitosan as potential antifungal has emerged, however, with few publications. Some chitosan derivatives studied as antifungal were N,Ocarboxymethyl chitosan [104], glycolchitosan [105], and thiourea derivative [106]. It was found that the hydrosoluble derivative $\mathrm{N}, \mathrm{O}$-carboxymethyl chitosan was less effective than chitosan in reducing the radial growth of the fungi $B$. cinerea and $R$. stolonifer, while the acid soluble derivative glycolchitosan was more effective than chitosan against the fungi $B$. cinerea and $P$. expansum. Once again, it looks that fungicidal effect depends on the charge density of the chitosan chain. Also, Rabea and colleagues [107-110] have synthesized a series of $\mathrm{N}$-alkyl and $\mathrm{N}$-aryl chitosan derivatives with superior fungicidal and insecticidal functions that founded for chitosan, although soluble only in acid conditions.

Recently, Badawy [111] has shown that the quaternary salts of alkyl chitosan derivatives also exhibit antifungal property against plant fungi Pythium debaryanum, B. cinerea and Fusarium oxysporum. Accordingly, in vitro results showed that the best antifungal quaternary salts were $\mathrm{N}$ octyl-N,N-dimethylchitosan against B. cinerea $(383 \mathrm{mg} / \mathrm{L})$, F. oxysporum $(812 \mathrm{mg} / \mathrm{L})$, and $P$. debaryanum $(440 \mathrm{mg} / \mathrm{L})$, on the basis of the effective concentration that caused $50 \%$ inhibition of mycelial growth $\left(\mathrm{EC}_{50}\right)$. TCM also showed a good activity with $\mathrm{EC}_{50}=1467,875$, and $907 \mathrm{mg} / \mathrm{L}$ respectively, for B. cinerea, F. oxysporum, and P. debaryanum. This is a good achievement when compared with chitosan that showed $\mathrm{EC}_{50}>3000 \mathrm{mg} / \mathrm{L}$ in all the cases. Despite the solubility of those salts in aqueous media, the author used a mild acetic acid solution to enhance salt solubility. The action of those quaternary salts was also effective against spore germination, generally increasing with an increase in the chain length of alkyl substituent.

Other hydrosoluble chitosan derivatives, bearing salicylaldehyde and pyridinium ion [112], were tested against some plant-threatening pathogenic fungi Cladosporium cucumerinum, Monilinia fructicola, Colletotrichum lagenarium, and F. oxysporum. The best performance of those salts was near $500-1000 \mu \mathrm{g} / \mathrm{mL}$.

Chitosan quaternary salt has shown good activity against fungal deterioration of in situ experiments with apple [113]. The TMC showed important antifungal activity against $P$. expansum which was strongly dependent on the characteristics of the polymer (Figure 8). By comparing the samples TMC1 $(\overline{D Q}=18 \%$, low solubility and low viscosity) and TMC2 ( $\overline{D Q} 45 \%$, high solubility and high viscosity), it was found that the latter presents superior antifungal activity. The chitosan derivatives N-butyl-N,Ndimethylchitosan, N-octyl-N,N-dimethylchitosan, and $\mathrm{N}$ dodecyl-N,N-dimethylchitosan also showed good antifungal activity (Figure 8). The introduction of alkyl substituents on the chitosan chain strongly decreases the polymer solubility, a property which seems to play a very important role in the antifungal activity. The chitosan derivative TMC dissolved in water solution exhibited moderate antifungal activity against $P$. digitatum and $B$. cinerea with fungal spread $28.6 \%$ and $45.5 \%$, respectively, as compared to the respective controls $34.9 \%$ and $51.5 \%$. As observed for P. expansum, the acetic 


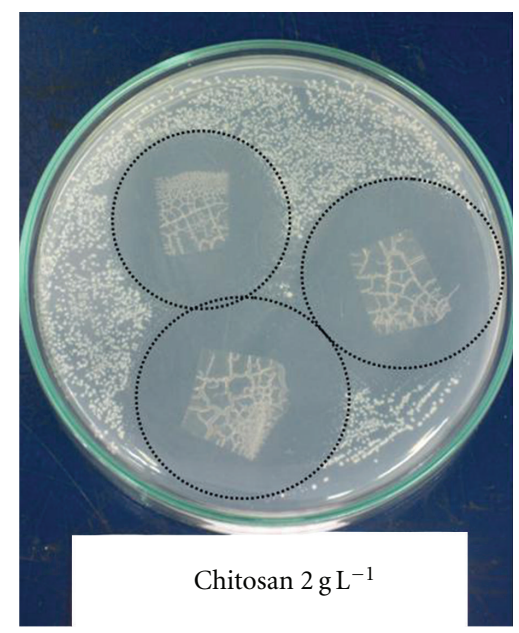

(a)

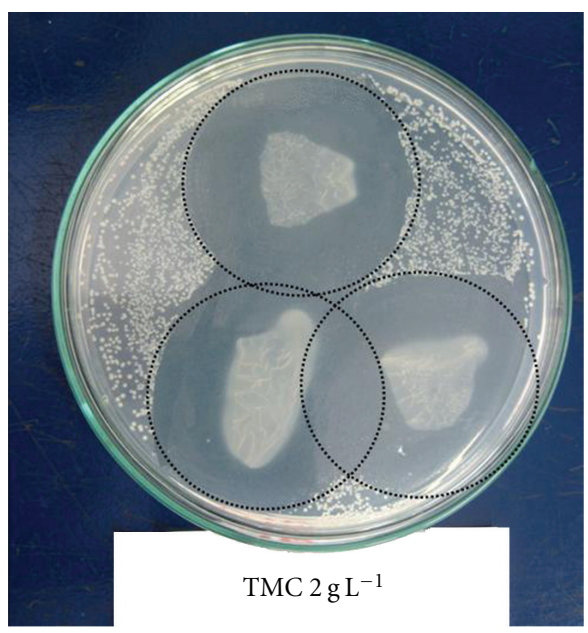

(b)

FIgURE 6: Examples of inhibitory effect of chitosan and TMC film against gram-positive bacteria S. aureus.

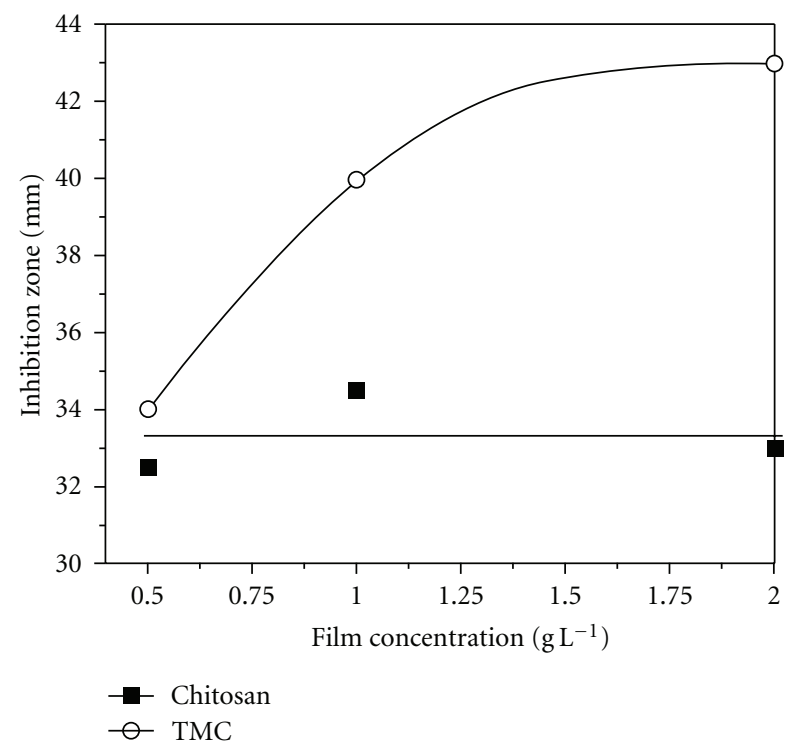

FIGURE 7: Inhibition zone in function of the film concentration as measured against the bacteria $S$. aureus.

acid medium was favorable to fungal spread on cut apple surface, reaching values of $100 \%$ and $87.1 \%$ for P. digitatum and $B$. cinerea, respectively, while both control samples were $100 \%$.

The mechanism of action of quaternary salts against fungi still debated but generally is attributed to formation of polyelectrolyte complex between different charged species, in a similar way that took for antibacterial action [111]. On the other hand, microscopic observation has shown that chitosan oligomers can also diffuse inside hyphae interfering on the enzymes activity responsible for the fungus growth [106].

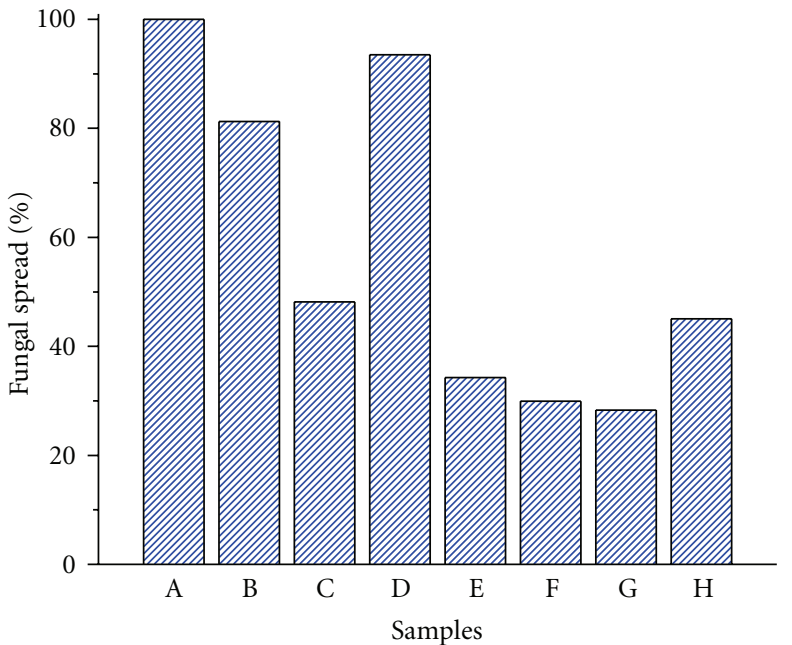

Figure 8: P. expansum colonies development on cut apple surface coated with different coating solutions after 7 days of storage in a greenhouse at $28^{\circ} \mathrm{C}$ and $80 \%$ humidity. (A) acetic acid control; (B) water control; (C) chitosan; (D) TMC1; (E) TMC2; (F) N-butylN,N-dimethylchitosan; (G) N-octyl-N,N-dimethylchitosan; (H) Ndodecyl-N,N-dimethylchitosan.

\section{Conclusion}

Quaternary salts of chitosan can be prepared with different degree of substitution mainly via methyl iodide or dimethylsulfate synthetic route. The last one shows the advantage of better control and reproducibility of the reaction steps. New and more security synthetic routes, free of hazardous methylant agent, can be developed to attenuate the purification costs for grade suitable for pharmaceutical and food areas. The water solubility is attained by introduction of $\mathrm{CH}_{3}$ moiety in the amino group, generating a permanent cationic polyelectrolyte. This feature enhances the chitosan 
applicability in a large $\mathrm{pH}$ range opening up a broad range of possibilities. Ordinary, by increasing the reaction time and reaction steps, a higher degree of $\mathrm{N}$-quaternization is achieved. However, the overmethylation can yield products with low degrees of substitution and polymerization. The antifungal activity represents a potential application as edible coating and film for this hydrosoluble derivative once the acid medium used for preparation of chitosan solution is very aggressive to cut fruit tissue. Regarding the antibacterial activity, it revealed higher inhibition against gram-positive than gram-negative bacteria. Finally, nanoparticles-based quaternary salts promise to improve these already cited properties. TMC and other chitosan quaternary salts have effectively antimicrobial activity; however, experiments in situ must help the applications in real conditions.

\section{Acknowledgments}

This work was supported by FAPESP, CNPq, and Embrapa.

\section{References}

[1] M. L. Wolfrom, J. R. Vercellotti, and D. Horton, "Methylation studies on carboxyl-reduced heparin- 2-amino-2-deoxy-3,6di-O-methyl-alpha-d-glucopyranose from the methylation of chitosan," Journal of Organic Chemistry, vol. 29, no. 3, pp. 547-550, 1964.

[2] L. A. Nudga, E. A. Plisko, and S. N. Danilov, "Cyanoethylation of chitosan," Zhurnal Obshchei Khimii, vol. 45, no. 5, pp. 1145-1149, 1975.

[3] L. A. Nudga, E. A. Plisko, and S. N. Danilov, "O-alkylation of chitosan," Zhurnal Obshchei Khimii, vol. 43, no. 12, pp. 2752-2756, 1973.

[4] L. A. Nudga, E. A. Plisko, and S. N. Danilov, "N-alkylation of chitosan," Zhurnal Obshchei Khimii, vol. 43, no. 12, pp. 2756-2760, 1973.

[5] R. A. A. Muzzarelli and F. Tanfani, "The $N$-permethylation of chitosan and the preparation of $N$-trimethyl chitosan iodide," Carbohydrate Polymers, vol. 5, no. 4, pp. 297-307, 1985.

[6] A. Domard, M. Rinaudo, and C. Terrassin, "New method for the quaternization of chitosan," International Journal of Biological Macromolecules, vol. 8, no. 2, pp. 105-107, 1986.

[7] A. Domard, C. Gey, M. Rinaudo, and C. Terrassin, ${ }^{13} \mathrm{C}$ and ${ }^{1} \mathrm{H}$ n.m.r. spectroscopy of chitosan and $\mathrm{N}$-trimethyl chloride derivatives," International Journal of Biological Macromolecules, vol. 9, no. 4, pp. 233-237, 1987.

[8] P. Dung, M. Milas, M. Rinaudo, and J. Desbrières, "Water soluble derivatives obtained by controlled chemical modifications of chitosan," Carbohydrate Polymers, vol. 24, no. 3, pp. 209-214, 1994.

[9] J. Murata, Y. Ohya, and T. Ouchi, "Possibility of application of quaternary chitosan having pendant galactose residues as gene delivery tool," Carbohydrate Polymers, vol. 29, no. 1, pp. 69-74, 1996.

[10] J. Murata, Y. Ohya, and T. Ouchi, "Design of quaternary chitosan conjugate having antennary galactose residues as a gene delivery tool," Carbohydrate Polymers, vol. 32, no. 2, pp. 105109, 1997.

[11] T. Kean, S. Roth, and M. Thanou, "Trimethylated chitosans as non-viral gene delivery vectors: cytotoxicity and transfection efficiency," Journal of Controlled Release, vol. 103, no. 3, pp. 643-653, 2005.
[12] S. R. Mao, U. Bakowsky, A. Jintapattanakit, and T. Kissel, "Self-assembled polyelectrolyte nanocomplexes between chitosan derivatives and insulin," Journal of Pharmaceutical Sciences, vol. 95, no. 5, pp. 1035-1048, 2006.

[13] Z. W. Mao, L. Ma, Y. Jiang, M. Yan, C. Y. Gao, and J. C. Shen, "N,N,N-trimethylchitosan chloride as a gene vector: synthesis and application," Macromolecular Bioscience, vol. 7, no. 6, pp. 855-863, 2007.

[14] O. Germershaus, S. R. Mao, J. Sitterberg, U. Bakowsky, and T. Kissel, "Gene delivery using chitosan, trimethyl chitosan or polyethylenglycol-graft-trimethyl chitosan block copolymers: establishment of structure-activity relationships in vitro," Journal of Controlled Release, vol. 125, no. 2, pp. 145-154, 2008.

[15] W. Sajomsang, U. Ruktanonchai, P. Gonil, V. Mayen, and P. Opanasopit, "Methylated $\mathrm{N}$-aryl chitosan derivative/DNA complex nanoparticles for gene delivery: synthesis and structure-activity relationships," Carbohydrate Polymers, vol. 78, no. 4, pp. 743-752, 2009.

[16] M. Werle, H. Takeuchi, and A. Bernkop-Schnurch, "Modified chitosans for oral drug delivery," Journal of Pharmaceutical Sciences, vol. 98, no. 5, pp. 1643-1656, 2009.

[17] M. N. V. R. Kumar, "A review of chitin and chitosan applications," Reactive \& Functional Polymers, vol. 46, no. 1, pp. 1-27, 2000.

[18] I. Aranaz, M. Mengíbar, R. Harris et al., "Functional characterization of chitin and chitosan," Current Chemical Biology, vol. 3, no. 2, pp. 203-230, 2009.

[19] A. F. Kotze, H. L. Lueßen, B. J. de Leeuw, B. G. de Boer, J. C. Verhoef, and H. E. Junginger, "N-Trimethyl chitosan chloride as a potential absorption enhancer across mucosal surfaces: in vitro evaluation in intestinal epithelial cells (Caco-2)," Pharmaceutical Research, vol. 14, no. 9, pp. 1197-1202, 1997.

[20] A. F. Kotze, H. L. Lueßen, B. J. de Leeuw, B. G. de Boer, J. C. Verhoef, and H. E. Junginger, "Chitosans for enhanced delivery of therapeutic peptides across intestinal epithelia: in vitro evaluation in Caco-2 cell monolayers," International Journal of Biological Macromolecules, vol. 159, no. 2, pp. 243253, 1997.

[21] A. F. Kotze, H. L. Lueßen, B. J. de Leeuw, B. G. de Boer, J. C. Verhoef, and H. E. Junginger, "Comparison of the effect of different chitosan salts and $N$-trimethyl chitosan chloride on the permeability of intestinal epithelial cells (Caco-2)," Journal of Controlled Release, vol. 51, no. 1, pp. 35-46, 1998.

[22] A. B. Sieval, M. Thanou, A. F. Kotze, J. C. Verhoef, J. Brussee, and H. E. Junginger, "Preparation and NMR characterization of highly substituted $N$-trimethyl chitosan chloride," Carbohydrate Polymers, vol. 36, no. 2-3, pp. 157165, 1998.

[23] A. F. Kotze, M. M. Thanou, H. L. Lueßen, B. G. de Boer, J. C. Verhoef, and H. E. Junginger, "Effect of the degree of quaternization of $\mathrm{N}$-trimethyl chitosan chloride on the permeability of intestinal epithelial cells (Caco-2)," European Journal of Pharmaceutics and Biopharmaceutics, vol. 47, no. 3, pp. 269-274, 1999.

[24] M. M. Thanou, A. F. Kotze, T. Scharringhausen et al., "Effect of degree of quaternization of $N$-trimethyl chitosan chloride for enhanced transport of hydrophilic compounds across intestinal Caco-2 cell monolayers," Journal of Controlled Release, vol. 64, no. 1-3, pp. 15-25, 2000.

[25] J. H. Hamman and A. F. Kotze, "Effect of the type of base and number of reaction steps on the degree of quaternization and 
molecular weight of $\mathrm{N}$-trimethyl chitosan chloride," Drug Development and Industrial Pharmacy, vol. 27, no. 5, pp. 373380, 2001.

[26] J. H. Hamman, M. Stander, and A. F. Kotze, "Effect of the degree of quaternisation of $\mathrm{N}$-trimethyl chitosan chloride on absorption enhancement: in vivo evaluation in rat nasal epithelia," International Journal of Pharmaceutics, vol. 232, no. 1-2, pp. 235-242, 2002.

[27] D. Snyman, J. H. Hamman, J. S. Kotze, J. E. Rollings, and A. F. Kotze, "The relationship between the absolute molecular weight and the degree of quaternisation of $\mathrm{N}$-trimethyl chitosan chloride," Carbohydrate Polymers, vol. 50, no. 2, pp. 145-150, 2002.

[28] S. M. van der Merwe, J. C. Verhoef, J. H. M. Verheijden, A. F. Kotze, and H. E. Junginger, "Trimethylated chitosan as polymeric absorption enhancer for improved peroral delivery of peptide drugs," European Journal of Pharmaceutics and Biopharmaceutics, vol. 58, no. 2, pp. 225-235, 2004.

[29] A. Polnok, G. Borchard, J. C. Verhoef, N. Sarisuta, and H. E. Junginger, "Influence of methylation process on the degree of quaternization of $N$-trimethyl chitosan chloride," European Journal of Pharmaceutics and Biopharmaceutics, vol. 57, no. 1, pp. 77-83, 2004.

[30] C. Jonker-Venter, D. Snyman, C. J. Van Rensburg et al., "Low molecular weight quaternised chitosan (II): in vitro assessment of absorption enhancing properties," Pharmazie, vol. 61, no. 4, pp. 301-305, 2006.

[31] G. Sandri, S. Rossi, M. C. Bonferoni et al., "Buccal penetration enhancement properties of $\mathrm{N}$-trimethyl chitosan: influence of quaternization degree on absorption of a high molecular weight molecule," International Journal of Pharmaceutics, vol. 297, no. 1-2, pp. 146-155, 2005.

[32] G. Sandri, S. Rossi, M. C. Bonferoni et al., "Influence of $N$ trimethylation degree on buccal penetration enhancement properties of $N$-trimethyl chitosan: absorption of a high molecular weight molecule," European Journal of Pharmaceutical Sciences, vol. 25, supplement 1, pp. S8-S10, 2005.

[33] B. I. Florea, M. Thanou, H. E. Junginger, and G. Borchard, "Enhancement of bronchial octreotide absorption by chitosan and $N$-trimethyl chitosan shows linear in vitro/in vivo correlation," Journal of Controlled Release, vol. 110, no. 2, pp. 353-361, 2006.

[34] Y. Zambito, C. Zaino, S. Burchielli, V. Carelli, M. F. Serafini, and G. Di Colo, "Novel quaternary ammonium chitosan derivatives for the promotion of intraocular drug absorption," Journal of Drug Delivery Science and Technology, vol. 17, no. 1, pp. 19-24, 2007.

[35] W. He, X. X. Guo, and M. Zhang, "Transdermal permeation enhancement of $\mathrm{N}$-trimethyl chitosan for testosterone," International Journal of Pharmaceutics, vol. 356, no. 1-2, pp. 82-87, 2008.

[36] M. C. Bonferoni, G. Sandri, S. Rossi, F. Ferrari, and C. Caramella, "Chitosan and its salts for mucosal and transmucosal delivery," Expert Opinion on Drug Delivery, vol. 6, no. 9, pp. 923-939, 2009.

[37] V. K. Mourya and N. N. Inamdar, "Trimethyl chitosan and its applications in drug delivery," Journal of Materials Science, vol. 20, no. 5, pp. 1057-1079, 2009.

[38] J. K. Sahni, S. Chopra, F. J. Ahmad, and R. K. Khar, "Potential prospects of chitosan derivative trimethyl chitosan chloride (TMC) as a polymeric absorption enhancer: synthesis, characterization and applications," Journal of Pharmacy and Pharmacology, vol. 60, no. 9, pp. 1111-1119, 2008.

[39] G. Lang, H. Wendel, and S. Birkel, "Quaternary chitosan salts," in Chitin Handbook, R. A. A. Muzzarelli and M. G. Peter, Eds., pp. 384-389, European Chitin Society press, Grottammare, Italy, 1997.

[40] C. H. Kim, J. W. Choi, H. J. Chun, and K. S. Choi, "Synthesis of chitosan derivatives with quaternary ammonium salt and their antibacterial activity," Polymer Bulletin, vol. 38, no. 4, pp. 387-393, 1997.

[41] Z. Jia, D. Shen, and W. Xu, "Synthesis and antibacterial activities of quaternary ammonium salt of chitosan," Carbohydrate Research, vol. 333, no. 1, pp. 1-6, 2001.

[42] W. Sajomsang, S. Tantayanon, V. Tangpasuthadol, and W. H. Daly, "Synthesis of methylated chitosan containing aromatic moieties: chemoselectivity and effect on molecular weight," Carbohydrate Polymers, vol. 72, no. 4, pp. 740-750, 2008.

[43] W. Sajomsang, P. Gonil, and S. Saesoo, "Synthesis and antibacterial activity of methylated N-(4-N,N-dimethylaminocinnamyl) chitosan chloride," European Polymer Journal, vol. 45, no. 8, pp. 2319-2328, 2009.

[44] T. Xu, M. Xin, M. Li, H. Huang, and S. Zhou, "Synthesis, characteristic and antibacterial activity of $N, N, N$-trimethyl chitosan and its carboxymethyl derivatives," Carbohydrate Polymers, vol. 81, no. 4, pp. 931-936, 2010.

[45] Ö. V. Rúnarsson, J. Holappa, C. Malainer et al., "Antibacterial activity of $\mathrm{N}$-quaternary chitosan derivatives: synthesis, characterization and structure activity relationship (SAR) investigations," European Polymer Journal, vol. 46, no. 6, pp. 1251-1267, 2010.

[46] E. Curti, D. de Britto, and S. P. Campana-Filho, "Methylation of chitosan with iodomethane: effect of reaction conditions on chemoselectivity and degree of substitution," Macromolecular Bioscience, vol. 3, no. 10, pp. 571-576, 2003.

[47] D. de Britto and S. P. Campana-Filho, "A kinetic study on the thermal degradation of N,N,N-trimethylchitosan," Polymer Degradation and Stability, vol. 84, no. 2, pp. 353-361, 2004.

[48] E. Curti and S. P. Campana-Filho, "Viscosity behavior of chitosan and $N, N, N$-trimethylchitosan chloride salts in acid-free aqueous solution," Journal of Macromolecular Science, vol. 43, no. 3, pp. 555-572, 2006.

[49] D. de Britto and O. B. G. Assis, "A novel method for obtaining a quaternary salt of chitosan," Carbohydrate Polymers, vol. 69, no. 2, pp. 305-310, 2007.

[50] D. de Britto and O. B. G. Assis, "Synthesis and mechanical properties of quaternary salts of chitosan-based films for food application," International Journal of Biological Macromolecules, vol. 41, no. 2, pp. 198-203, 2007.

[51] D. de Britto, L. A. Forato, and O. B. G. Assis, "Determination of the average degree of quaternization of $\mathrm{N}, \mathrm{N}, \mathrm{N}$ trimethylchitosan by solid state ${ }^{13} \mathrm{C}$ NMR," Carbohydrate Polymers, vol. 74, no. 1, pp. 86-91, 2008.

[52] R. J. Verheul, M. Amidi, S. van der Wal, E. van Riet, W. Jiskoot, and W. E. Hennink, "Synthesis, characterization and in vitro biological properties of $O$-methyl free $N, N, N$ trimethylated chitosan," Biomaterials, vol. 29, no. 27, pp. 3642-3649, 2008.

[53] O. V. Rúnarsson, J. Holappa, S. Jónsdóttir, H. Steinsson, and M. Másson, "N-selective 'one pot' synthesis of highly N-substituted trimethyl chitosan (TMC)," Carbohydrate Polymers, vol. 74, no. 3, pp. 740-744, 2008. 
[54] Y. M. Xu, Y. M. Du, R. H. Huang, and L. Gao, "Preparation and modification of $\mathrm{N}$-(2-hydroxyl) propyl-3-trimethyl ammonium chitosan chloride nanoparticle as a protein carrier," Biomaterials, vol. 24, no. 27, pp. 5015-5022, 2003.

[55] M. Amidi, S. G. Romeijn, G. Borchard, H. E. Junginger, W. E. Hennink, and W. Jiskoot, "Preparation and characterization of protein-loaded $N$-trimethyl chitosan nanoparticles as nasal delivery system," Journal of Controlled Release, vol. 111, no. 1-2, pp. 107-116, 2006.

[56] M. Amidi, S. G. Romeijn, J. C. Verhoef et al., " $N$-Trimethyl chitosan (TMC) nanoparticles loaded with influenza subunit antigen for intranasal vaccination: biological properties and immunogenicity in a mouse model," Vaccine, vol. 25, no. 1, pp. 144-153, 2007.

[57] B. Sayin, S. Somavarapu, X. W. Li et al., "Mono-Ncarboxymethyl chitosan (MCC) and $N$-trimethyl chitosan (TMC) nanoparticles for non-invasive vaccine delivery," International Journal of Pharmaceutics, vol. 363, no. 1-2, pp. 139-148, 2008.

[58] B. Slutter, L. Plapied, V. Fievez et al., "Mechanistic study of the adjuvant effect of biodegradable nanoparticles in mucosal vaccination," Journal of Controlled Release, vol. 138, no. 2, pp. 113-121, 2009.

[59] F. Chen, Z. R. Zhang, and Y. Huang, "Evaluation and modification of $N$-trimethyl chitosan chloride nanoparticles as protein carriers," International Journal of Pharmaceutics, vol. 336, no. 1, pp. 166-173, 2007.

[60] Y. Sun and A. J. Wan, "Preparation of nanoparticles composed of chitosan and its derivatives as delivery systems for macromolecules," Journal of Applied Polymer Science, vol. 105, no. 2, pp. 552-561, 2007.

[61] F. Chen, Z. R. Zhang, F. Yuan, X. Qin, M. T. Wang, and Y. Huang, "In vitro and in vivo study of $N$-trimethyl chitosan nanoparticles for oral protein delivery," International Journal of Pharmaceutics, vol. 349, no. 1-2, pp. 226-233, 2008.

[62] A. M. M. Sadeghi, F. A. Dorkoosh, M. R. Avadi, P. Saadat, M. Rafiee-Tehrani, and H. E. Junginger, "Preparation, characterization and antibacterial activities of chitosan, $N$-trimethyl chitosan (TMC) and $N$-diethylmethyl chitosan (DEMC) nanoparticles loaded with insulin using both the ionotropic gelation and polyelectrolyte complexation methods," International Journal of Pharmaceutics, vol. 355, no. 1-2, pp. 299-306, 2008.

[63] J. Haas, M. N. V. R. Kumar, G. Borchard, U. Bakowsky, and C. M. Lehr, "Preparation and characterization of chitosan and trimethyl-chitosan modified poly-( $\varepsilon$-caprolactone) nanoparticles as DNA carriers," AAPS PharmSciTech, vol. 6, no. 1, pp. E22-E30, 2005.

[64] S. Mao, O. Germershaus, D. Fischer, T. Linn, R. Schnepf, and T. Kissel, "Uptake and transport of PEG-graft-trimethylchitosan copolymer-insulin nanocomplexes by epithelial cells," Pharmaceutical Research, vol. 22, no. 12, pp. 20582068, 2005.

[65] S. Mao, U. Bakowsky, A. Jintapattanakit, and T. Kissel, "Self-assembled polyelectrolyte nanocomplexes between chitosan derivatives and insulin," Journal of Pharmaceutical Sciences, vol. 95, no. 5, pp. 1035-1048, 2006.

[66] L. C. Yin, J. Y. Ding, C. B. He, L. M. Cui, C. Tang, and C. H. Yin, "Drug permeability and mucoadhesion properties of thiolated trimethyl chitosan nanoparticles in oral insulin delivery," Biomaterials, vol. 30, no. 29, pp. 5691-5700, 2009.
[67] Y. Ding, X. H. Xia, and C. Zhang, "Synthesis of metallic nanoparticles protected with $N, N, N$-trimethyl chitosan chloride via a relatively weak affinity," Nanotechnology, vol. 17, no. 16, pp. 4156-4162, 2006.

[68] X. J. Yuan, Z. R. Zhang, Q. G. Song, and Q. He, "Research on thymopentin loaded oral $N$-trimethyl chitosan nanoparticles," Archives of Pharmacal Research, vol. 29, no. 9, pp. 795-799, 2006.

[69] S. Cafaggi, E. Russo, R. Stefani et al., "Preparation and evaluation of nanoparticles made of chitosan or $N$-trimethyl chitosan and a cisplatin-alginate complex," Journal of Controlled Release, vol. 121, no. 1-2, pp. 110-123, 2007.

[70] Y. Zheng, Z. Cai, X. Song et al., "Preparation and characterization of folate conjugated $N$-trimethyl chitosan nanoparticles as protein carrier targeting folate receptor: in vitro studies," Journal of Drug Targeting, vol. 17, no. 4, pp. 294-303, 2009.

[71] C. Zhang, Y. Ding, Q. E. Ping, and L. L. Yu, "Novel chitosanderived nanomaterials and their micelle-forming properties," Journal of Agricultural and Food Chemistry, vol. 54, no. 22, pp. 8409-8416, 2006.

[72] C. Zhang, Y. Ding, L. L. Yu, and Q. Ping, "Polymeric micelle systems of hydroxycamptothecin based on amphiphilic $\mathrm{N}$-alkyl-N-trimethyl chitosan derivatives," Colloids and Surfaces B, vol. 55, no. 2, pp. 192-199, 2007.

[73] F. L. Mi, Y. Y. Wu, Y. H. Lin et al., "Oral delivery of peptide drugs using nanoparticles self-assembled by $\operatorname{poly}(\gamma$ glutamic acid) and a chitosan derivative functionalized by trimethylation," Bioconjugate Chemistry, vol. 19, no. 6, pp. 1248-1255, 2008.

[74] A. M. M. Sadeghi, F. A. Dorkoosh, M. R. Avadi et al., "Permeation enhancer effect of chitosan and chitosan derivatives: comparison of formulations as soluble polymers and nanoparticulate systems on insulin absorption in Caco-2 cells," European Journal of Pharmaceutics and Biopharmaceutics, vol. 70, no. 1, pp. 270-278, 2008.

[75] K. Van de Velde and P. Kiekens, "Structure analysis and degree of substitution of chitin, chitosan and dibutyrylchitin by FT-IR spectroscopy and solid state ${ }^{13} \mathrm{C}$ NMR," Carbohydrate Polymers, vol. 58, no. 4, pp. 409-416, 2004.

[76] W. Boonyo, H. E. Junginger, N. Waranuch, A. Polnok, and T. Pitaksuteepong, "Chitosan and trimethyl chitosan chloride (TMC) as adjuvants for inducing immune responses to ovalbumin in mice following nasal administration," Journal of Controlled Release, vol. 121, no. 3, pp. 168-175, 2007.

[77] A. Jintapattanakit, S. Mao, T. Kissel, and V. B. Junyaprasert, "Physicochemical properties and biocompatibility of $\mathrm{N}$ trimethyl chitosan: effect of quaternization and dimethyl ation," European Journal of Pharmaceutics and Biopharmaceutics, vol. 70, no. 2, pp. 563-571, 2008.

[78] R. J. Verheul, M. Amidi, M. J. van Steenbergen, E. van Riet, W. Jiskoot, and W. E. Hennink, "Influence of the degree of acetylation on the enzymatic degradation and in vitro biological properties of trimethylated chitosans," Biomaterials, vol. 30, no. 18, pp. 3129-3135, 2009.

[79] N. Hagenaars, R. J. Verheul, I. Mooren et al., "Relationship between structure and adjuvanticity of $N, N, N$-trimethyl chitosan (TMC) structural variants in a nasal influenza vaccine," Journal of Controlled Release, vol. 140, no. 2, pp. 126-133, 2009.

[80] B. Slütter, P. C. Soema, Z. Ding, R. Verheul, W. Hennink, and W. Jiskoot, "Conjugation of ovalbumin to trimethyl chitosan improves immunogenicity of the antigen," Journal of Controlled Release, vol. 143, no. 2, pp. 207-214, 2010. 
[81] P. Vongchan, Y. Wutti-In, W. Sajomsang, P. Gonil, S. Kothan, and R. J. Linhardt, "N,N,N-Trimethyl chitosan nanoparticles for the delivery of monoclonal antibodies against hepatocellular carcinoma cells," Carbohydrate Polymers, vol. 85, no. 1, pp. 215-220, 2011.

[82] D. de Britto, F. R. Frederico, and O. B. Garrido Assis, "Optimization of $N, N, N$-trimethylchitosan synthesis by factorial design," Polymer International, vol. 60, no. 6, pp. 910-915, 2011.

[83] D. de Britto, Estudos da obtenção e das propriedades de carboximetilcelulose (CMC) e N,N,N-trimetilquitosana (TMQ) e das interações do complexo polieletrolítico CMC/TMC com $\mathrm{Cu}^{2+}$, ácido húmico e atrazina, Ph.D. thesis, USP/IQSC, São Carlos, Brazil, 2003.

[84] D. de Britto and O. B. G. Assis, "Hydrophilic and morphological aspects of films based on quaternary salts of chitosan for edible applications," Packaging Technology and Science, vol. 23, no. 2, pp. 111-119, 2010.

[85] R. C. Goy, D. de Britto, and O. B. G. Assis, "A Review of the Antimicrobial Activity of Chitosan," Polimeros: Ciência e Tecnologia, vol. 19, no. 3, pp. 241-247, 2009.

[86] M. Kong, X. G. Chen, K. Xing, and H. J. Park, "Antimicrobial properties of chitosan and mode of action: a state of the art review," International Journal of Food Microbiology, vol. 144, no. 1, pp. 51-63, 2010.

[87] E. I. Rabea, M. E. -T. Badawy, C. V. Stevens, G. Smagghe, and W. Steurbaut, "Chitosan as antimicrobial agent: applications and mode of action," Biomacromolecules, vol. 4, no. 6, pp. 1457-1465, 2003.

[88] Ö. V. Rúnarsson, J. Holappa, T. Nevalainen et al., "Antibacterial activity of methylated chitosan and chitooligomer derivatives: synthesis and structure activity relationships," European Polymer Journal, vol. 43, no. 6, pp. 2660-2671, 2007.

[89] M. R. Avadi, A. M. M. Sadeghi, A. Tahzibi et al., "Diethylmethyl chitosan as an antimicrobial agent: synthesis, characterization and antibacterial effects," European Polymer Journal, vol. 40, no. 7, pp. 1355-1361, 2004.

[90] W. Sajomsang, S. Tantayanon, V. Tangpasuthadol, and W. H. Daly, "Quaternization of $\mathrm{N}$-aryl chitosan derivatives: synthesis, characterization, and antibacterial activity," Carbohydrate Research, vol. 344, no. 18, pp. 2502-2511, 2009.

[91] W. Sajomsang, P. Gonil, and S. Tantayanon, "Antibacterial activity of quaternary ammonium chitosan containing mono or disaccharide moieties: preparation and characterization," International Journal of Biological Macromolecules, vol. 44, no. 5, pp. 419-427, 2009.

[92] J. Y. Kim, J. K. Lee, T. S. Lee, and W. H. Park, "Synthesis of chitooligosaccharide derivative with quaternary ammonium group and its antimicrobial activity against Streptococcus mutans," International Journal of Biological Macromolecules, vol. 32, no. 1-2, pp. 23-27, 2003.

[93] R. Belalia, S. Grelier, M. Benaissa, and V. Coma, "New bioactive biomaterials based on quaternized chitosan," Journal of Agricultural and Food Chemistry, vol. 56, no. 5, pp. 1582-1588, 2008.

[94] M. Ignatova, K. Starbova, N. Markova, N. Manolova, and I. Rashkov, "Electrospun nano-fibre mats with antibacterial properties from quaternised chitosan and poly(vinyl alcohol)," Carbohydrate Research, vol. 341, no. 12, pp. 2098-2107, 2006.

[95] M. Ignatova, N. Manolova, and I. Rashkov, "Novel antibacterial fibers of quaternized chitosan and poly(vinyl pyrrolidone) prepared by electrospinning," European Polymer Journal, vol. 43, no. 4, pp. 1112-1122, 2007.
[96] X. Fu, Y. Shen, X. Jiang, D. Huang, and Y. Yan, "Chitosan derivatives with dual-antibacterial functional groups for antimicrobial finishing of cotton fabrics," Carbohydrate Polymers, vol. 85, no. 1, pp. 221-227, 2011.

[97] R. C. Goy, D. Britto, and O. B. G. Assis, "Antimicrobial analysis of gels and films from chitosan and N,N,N-trimethyl chitosan," in Advances in Chitin Science, T. T. Franco and M. G. Peter, Eds., vol. 12, pp. 129-132, Unicamp/University of Potsdam, Potsdam, Germany, 2010.

[98] F. Shahidi, J. K. V. Arachchi, and Y. -J. Jeon, "Food applications of chitin and chitosans," Trends in Food Science and Technology, vol. 10, no. 2, pp. 37-51, 1999.

[99] S. B. Baños, A. N. H. Lauzardo, M. G. V. del Valle et al., "Chitosan as a potential natural compound to control pre and postharvest diseases of horticultural commodities," Crop Protection, vol. 25, no. 2, pp. 108-118, 2006.

[100] H. K. No, S. P. Meyers, W. Prinyawiwatkul, and Z. Xu, "Applications of chitosan for improvement of quality and shelf life of foods: a review," Journal of Food Science, vol. 72, no. 5, pp. R87-R100, 2007.

[101] T. Yu, H. Y. Li, and X. D. Zheng, "Synergistic effect of chitosan and Cryptococcus laurentii on inhibition of Penicillium expansum infections," International Journal of Food Microbiology, vol. 114, no. 3, pp. 261-266, 2007.

[102] C. L. Wilson, A. El-Ghaouth, and M. E. Wisniewski, "Synergistic combinations of natural of compounds that control decay of fruits and vegetables and reduce contamination by food borne human pathogens," Patent number US $20030113421 \mathrm{~A} 1,2003$.

[103] C. L. Wilson and A. El-Ghaouth, "Biological coating with a protective and curative effect for the control of postharvest decay," Patent number US 6,423,310 B1, 2002.

[104] A. El-Ghaouth, J. Arul, A. Asselin, and N. Benhamou, "Antifungal activity of chitosan on postharvest pathogensinduction of morphological and cytological alterations in Rhizopus-stolonifer," Mycological Research, vol. 96, no. 9, pp. 769-779, 1992.

[105] A. El-Ghaouth, J. L. Smilanick, and C. L. Wilson, "Enhancement of the performance of Candida saitoana by the addition of glycolchitosan for the control of postharvest decay of apple and citrus fruit," Postharvest Biology and Technology, vol. 19, no. 1, pp. 103-110, 2000.

[106] M. Eweis, S. S. Elkholy, and M. Z. Elsabee, "Antifungal efficacy of chitosan and its thiourea derivatives upon the growth of some sugar-beet pathogens," International Journal of Biological Macromolecules, vol. 38, no. 1, pp. 1-8, 2006.

[107] M. E. I. Badawy, E. I. Rabea, T. M. Rogge et al., "Synthesis and fungicidal activity of new N,O-acyl chitosan derivatives," Biomacromolecules, vol. 5, no. 2, pp. 589-595, 2004.

[108] E. I. Rabea, M. E. I. Badawy, T. M. Rogge et al., "Insecticidal and fungicidal activity of new synthesized chitosan derivatives," Pest Management Science, vol. 61, no. 10, pp. 951-960, 2005.

[109] E. I. Rabea, M. E. I. Badawy, T. M. Rogge et al., "Enhancement of fungicidal and insecticidal activity by reductive alkylation of chitosan," Pest Management Science, vol. 62, no. 9, pp. 890-897, 2006.

[110] E. I. Rabea, M. E. I. Badawy, W. Steurbaut, and C. V. Stevens, "In vitro assessment of $N$-(benzyl)chitosan derivatives against some plant pathogenic bacteria and fungi," European Polymer Journal, vol. 45, no. 1, pp. 237-245, 2009.

[111] M. E. I. Badawy, "Structure and antimicrobial activity relationship of quaternary $N$-alkyl chitosan derivatives against 
some plant pathogens," Journal of Applied Polymer Science, vol. 117, no. 2, pp. 960-969, 2010.

[112] R. Li, Z. Guo, and P. Jiang, "Synthesis, characterization, and antifungal activity of novel quaternary chitosan derivatives," Carbohydrate Research, vol. 345, no. 13, pp. 1896-1900, 2010.

[113] D. Britto, S. P. Campana Filho, and O. B. G. Assis, "Chitosanbased coatings for lightly processed food," in Proceedings of the 10th International Conference on Chitin and Chitosan Advances in Chitin Science, A. Domard, E. Guibal, and K. M. Vårum, Eds., vol. 9, Montpellier, France, 2006. 


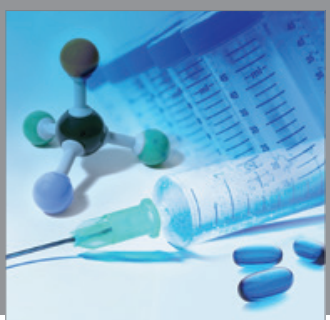

International Journal of

Medicinal Chemistry

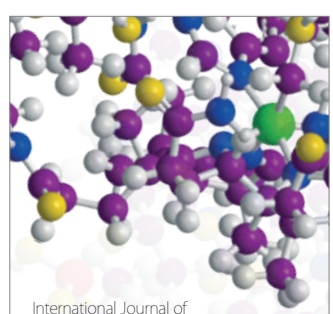

Carbohydrate Chemistry

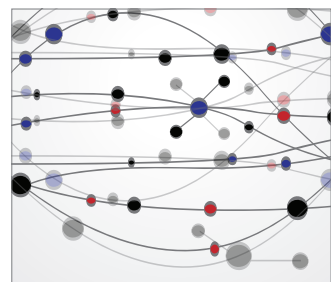

The Scientific World Journal
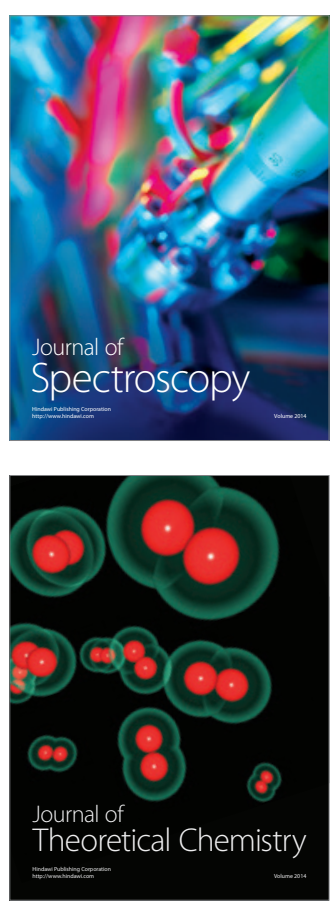
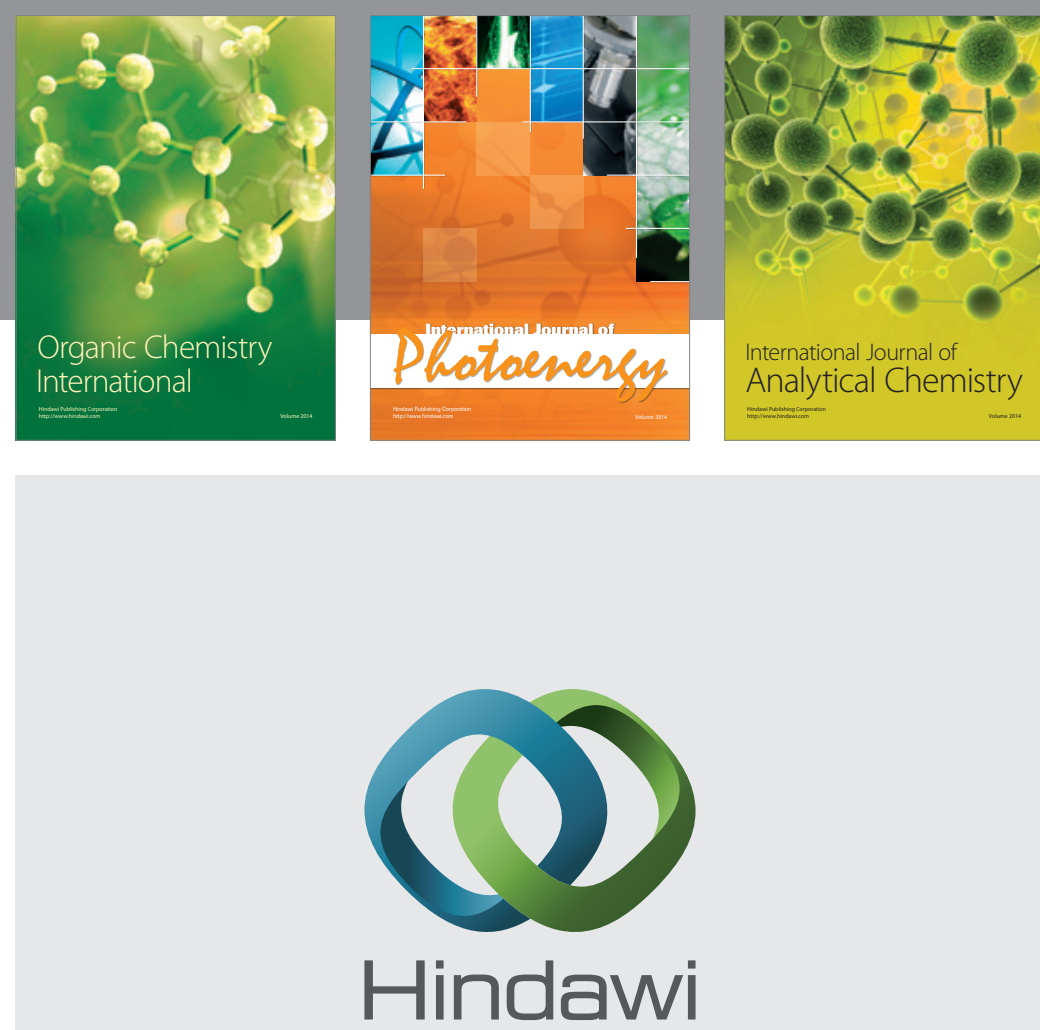

Submit your manuscripts at

http://www.hindawi.com
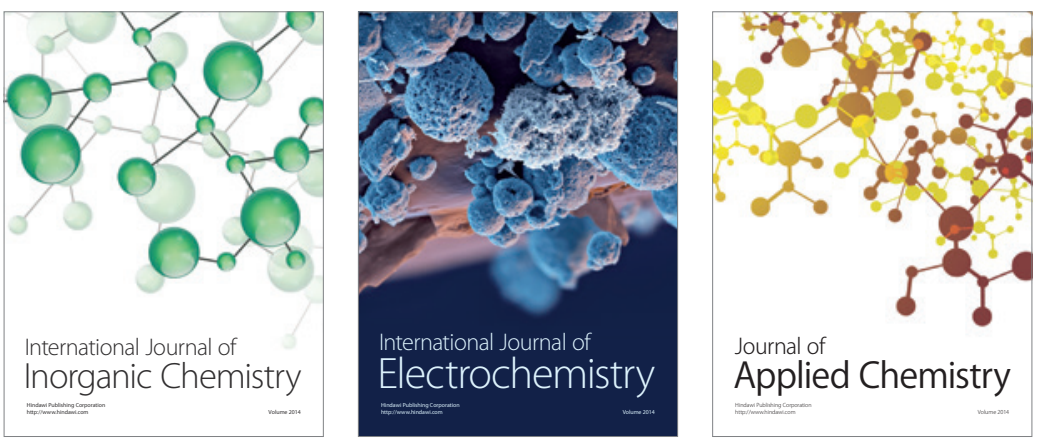

Journal of

Applied Chemistry
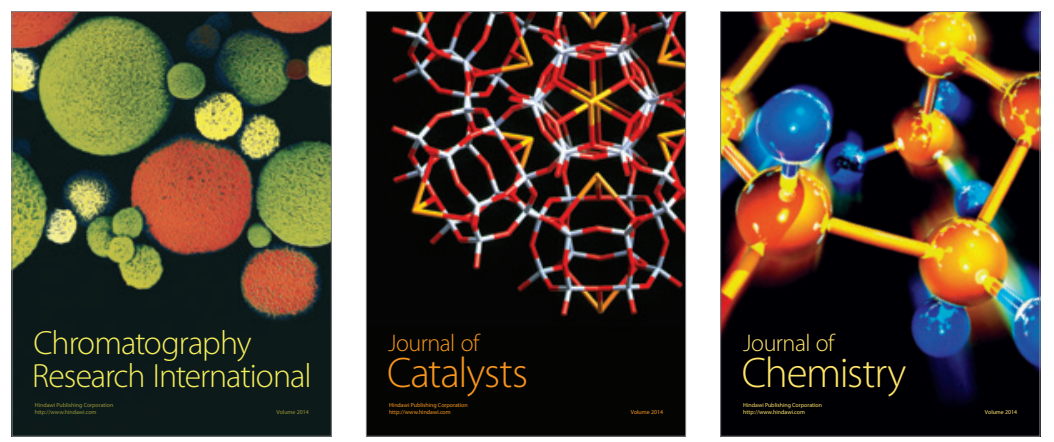
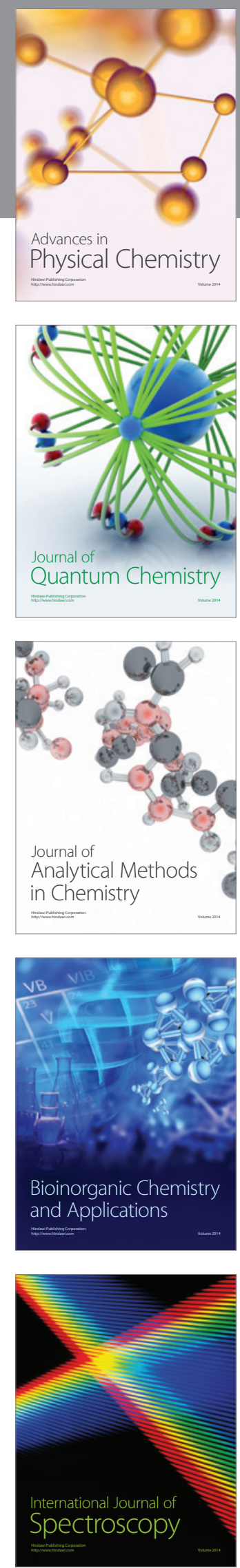